\title{
Vectors of Knowledge Society: Knowledge Management and E-learning
}

\author{
Luminita Giurgiu \\ Land Forces Academy, Sibiu, Romania
}

\begin{abstract}
The aim of this article is a research on concepts of knowledge management and e-learning motivated by the question concerning the way they improve education and training in the knowledge-based society. The two concepts are seen as tools that transform informational society into the knowledge society, so they are analyzed as vectors of the knowledge society. The study on the tendencies evolving on the technology and education realm reveals not only how e-learning and knowledge management affect the perspective of educational practice but ultimately, by demonstrating their convergence, the crucial role in improving organizational performance. The conclusions are outlined in light of the fact that providing knowledge is the both vectors' common goal, characterized by the democratization of information, communication, understanding, and cooperation.
\end{abstract}

Keywords: e-learning, knowledge management, knowledge society vectors

\section{Introduction}

Nowadays, the knowledge society requires an increasing number of knowledge society vectors. In scientific literature so far, two classes of vectors of the knowledge society were defined: technological vectors and functional vectors (Draganescu, 2008). The next technological vectors are considered:

- a developed Internet by: geographical extension, the use of broadband transmission of information, the coverage of each institution, each home, and each citizen in the network;

- intelligent agents, which are actually artificial intelligence expert systems, used for data mining and even formal findings on the nature of knowledge; they are very important because they will be used to many functional vectors knowledge society;

- intelligent environment for people's work and life;

- nanoelectronics, which will become the main physical medium for processing information, but also for many other functions.

As more and more areas of activity will be increasingly dependent on knowledge, the number of functional vectors can be quite large, such as:

- knowledge management for businesses, organizations, national, and local institutions;

- deepening knowledge about existence;

- globally moral use of knowledge management;

Luminita Giurgiu, Ph.D., associate professor, Land Forces Academy, Sibiu, Romania.

Correspondence concerning this article should be addressed to Luminita Giurgiu, Revolutiei Street No. 3-5, Sibiu, Romania. E-mail: lumigee35@gmail.com. 
- health care system to social and individual level;

- protecting the environment and ensuring sustainable society with a specific knowledge management;

- generating new knowledge technology;

- developing a culture of knowledge and innovation;

- an education system based on the information society and knowledge methods-e-learning.

Information with meaning and information to act is knowledge, so knowledge society is possible only grafted on the information society and it cannot be separately.

In the research process that is emergent and evolving, the research questions on how knowledge management and e-learning vectors affect the perspective of educational practice and how their convergence has a crucial role in improving organizational performance and will serve as signposts, foreshadowing the specific details of the study.

\section{Analysis of Knowledge Management as Vector}

Involving strategies and practices like identifying, creating, representing, distributing, retrieving, and sharing knowledge in order to focus on vital organizational objectives, the term "knowledge management" is a multidisciplinary one. These objectives refer to competitive advantage, improved performance, sharing of learned lessons, innovation, integration, and continuous improvement of the organization. The management's problem with respect to knowledge is seen in two ways that normally need to combine a general vision about organization and knowledge management:

- as an organization's management that is concerned with the use and integration of different types of knowledge;

- as knowledge management itself.

One of the first studies in the country on knowledge management was published in the work of Iancu (2001). In his study, emphasis is placed on the notion of intellectual capital and trained and innovative economic organization:

Because people work together collaborating, all human values may be higher than the sum of the parts, if the organization has managed to build a community where creative ability is stimulated. The future economic success will belong to the organization that is concerned, through training, with the continued development of its intellectual capital, the development of its knowledge base. (Iancu, 2001, p. 9)

Knowledge is considered as a strategic asset and sharing of knowledge is the key to fulfilling the organization objectives (Giurgiu, Barsan, \& Mosteanu, 2011). Very important components merge together because knowledge management engages:

- people (knowledge workers and knowledge authors);

- content (creating and managing data, information, and knowledge);

- technology (the technical infrastructure that enables the capture, storage, search, and delivery of content to those who need it, when they need it); a culture of knowledge.

The technical dimension of knowledge management, referred as knowledge management systems, addresses a class of information systems applied to manage organizational knowledge and make use of modern information technologies to support the organizational processes of knowledge creation, storage, retrieval, transfer, and application. Because such a system must uphold insights, truths, judgments, experiences, values, assumptions, and knowledge as components of intelligence, these applications can be sustained by several attributes like: 
- learning: more commonly used, users becoming more skilled;

- recovery through use: using the services which are significantly improving;

- anticipation: making recommendations with regard to the wishes of users;

- interactivity: mutual user system;

- customization: providing a unique configuration for a particular specification.

Placing knowledge management systems in the context of learning, it is definitively characterized by a complete cycle of the processes of knowledge creation and acquisition, knowledge capture, knowledge application, knowledge sharing, and knowledge evaluation.

All these aspects lead to the conclusion that in the knowledge based organization, the creation, dissemination, and utilization of knowledge by merging people, organizational structures, and technologies, are the main features of knowledge management in order to obtain effective learning, problem solving, and finally decision making.

\section{Analysis of E-learning as Vector}

The shift from knowledge as a set of knowledge, information, and data, to knowledge as a set of skills (know how to do/to act) results in a move of emphasis in education, from the exposure ex-cathedra to learning through experience/by practice, from the transmission and storing of information to the formation of skills, abilities, and competencies. So, new information and communication technologies change the perspective of educational practice, complementing the education with modern specific learning methodologies of the information society. E-learning technologies that are popular today are the result of evolution, both pedagogical and psychological methods of education and information and communication technology (web technologies, multimedia technologies, and communication technologies).

E-learning can be used for individual online courses or virtual universities, e-training within companies, and online workshops as a collaborative virtual space and to promote organizational learning. If in the virtual learning spaces there are didactic learning types like web-courses, interactive video-conferencing-courses, discussion forums, and multimedia-courses, in organizations based on information and knowledge, the learning process covers the entire organizational framework and is supported by knowledge management strategy adopted in the organization. The individual learning and especially collective learning will enrich the collective knowledge and the organization's intellectual capital; the notion of learning will mean more than simply training.

E-learning offers in essence, convenient, and efficient access to information and the latest knowledge, new and effective methods of teaching, learning, and assessment of knowledge, and training and ongoing training. Specific features of e-learning technologies bring new dimensions in education and can be complementary or alternative to traditional education. These features offer the possibility to organize online education on topics or themes, while traditional education is organized into groups/classes of age. An information society is born into an environment where the vast majority of its members have access to information and communication technology commonly used for both training and professional and personal activities. In this sense, e-learning is an alternative to lifelong learning in the information society of today or tomorrow.

From the point of view of e-learning, the important thing is to have the knowledge and skills necessary at the time it is required. Here it is considered the learning content management systems. According to Brandon Hall's glossary, learning content management system is an environment where developers can create, store, 
reuse, manage, and deliver learning content from a central object repository, usually a database (Retrieved from http://www.brandonhall.com/public/glossary/); the learning objects refer to "self-contained chunks of training content that can be assembled with other learning objects to create courses and curricula" (Retrieved from http://www.management.ase.ro/reveconomia/2008-2/11.pdf). Applications of this type allow the registration of training progress, record test and examinations' results in a training on-line program; educational material is aimed at completing the entire course. Most applications allow learning content management systems type of information transfer to other records management software of the whole educational process. It is remarkable that academic institutions were and are the vanguard of adopting new technologies to increase access to education and training.

\section{Knowledge Management and E-learning Convergence}

In the process of professional development, e-learning and knowledge management systems converge and affect each other and this depends on how they are designed and how they are used by learners:

- On one hand, if an e-learning module is designed to be completed by all learners or if a manager requires that members on a team complete it to qualify for a particular position, that is training. The important thing in e-learning is to have the knowledge and skills necessary at the time it is required;

- On the other hand, if an individual finds and accesses on his own an e-learning module in a knowledge repository just to learn about it, that is knowledge management. The important thing in knowledge management is to have the ability to apply the knowledge and skills necessary in a concrete work situation, when needed.

Integrated approach between knowledge management and e-learning is needed and beneficial in improving organizational performance. The community web portals with dynamic delivery and presentation of the content, similar to learning content management system, contains a repository of content that is modularized and arranged to facilitate access, authorized users adding or modifying the content to keep it current. To target individual user needs and interests, customized information formalized in learning objects can be aggregated and integrated within a particular working environment.

These aspects conclude that knowledge management and e-learning systems have common characteristics and features that include: common cooperation and synchronous/asynchronous communication tools; the same system architecture; similar rules of the access, the personalization of the delivered information; the same form of expression; etc.

It is noteworthy also the contribution of the e-learning applications and platforms to the development of knowledge management challenging processes, namely: capturing tacit knowledge of teachers, sharing their knowledge, and creating new knowledge.

\section{Conclusions}

The study shows that there is a natural fit between knowledge management and e-learning. Together it represents the professional development way of the future, in the knowledge based society that is characterized by dynamism and continuous renewal.

The complexity of the phenomena of modern society requires a knowledge base and skills increasingly richer: E-learning can be viewed as the core of the knowledge management life cycle and knowledge management tools and technologies can be successfully applied to e-learning. The use of knowledge management in e-learning definitely impacts the quality of the education on one hand; on the other hand, a 
properly implemented e-learning platform provides knowledge management infrastructure to support the educational sector. This is the way schools, colleges, and universities can really become organizations that learn in a demanding dynamic knowledge society.

\section{References}

Brandon Hall Group. (2015). LCMS technology. Retrieved from http://www.brandonhall.com/public/glossary/

Draganescu, M. (2008). Societatea informationala in era cunoasterii. Bucuresti: Academia Romana.

Giurgiu, L., Barsan, G., \& Mosteanu, D. (2011). Aspects of e-learning and knowledge management convergence in knowledge-based society. Proceedings from ICASS 2011 International Conference on Applied Social Science.

Iancu, S. (2001). Managementul cunostintelor. Retrieved from http://www.agir.ro/univers-ingineresc/

Lupsa-Tataru, D. (2008). The convergence between knowledge management and e-learning concepts. Retrieved from http://www.management.ase.ro/reveconomia/2008-2/11.pdf 